\title{
OPEN
}

\section{Author Correction: A Monte Carlo feasibility study for neutron based real-time range verification in proton therapy}

\author{
Kristian Smeland Ytre-Hauge $\mathbb{D}^{1}$, Kyrre Skjerdal ${ }^{2}$, John Mattingly ${ }^{3}$ \& Ilker Meric $\mathbb{C}^{3,4}$ \\ Correction to: Scientific Reports https://doi.org/10.1038/s41598-019-38611-w, published online 14 February 2019
}

This Article contains errors in Reference 16, which is incorrectly given as:

Lyoussi, A. et al. Conception of a New Recoil Proton Telescope for Real-Time Neutron Spectrometry in Proton-Therapy. EPJ Web of Conferences 170, 09001, https://doi.org/10.1051/epjconf/201817009001 (2018).

The correct reference is listed below:

Combe R. et al., Conception of a New Recoil Proton Telescope for Real-Time Neutron Spectrometry in Proton-Therapy. EPJ Web of Conferences 170, 09001, https://doi.org/10.1051/epjconf/201817009001 (2018).

\begin{abstract}
(c) (i) Open Access This article is licensed under a Creative Commons Attribution 4.0 International c. License, which permits use, sharing, adaptation, distribution and reproduction in any medium or format, as long as you give appropriate credit to the original author(s) and the source, provide a link to the Creative Commons license, and indicate if changes were made. The images or other third party material in this article are included in the article's Creative Commons license, unless indicated otherwise in a credit line to the material. If material is not included in the article's Creative Commons license and your intended use is not permitted by statutory regulation or exceeds the permitted use, you will need to obtain permission directly from the copyright holder. To view a copy of this license, visit http://creativecommons.org/licenses/by/4.0/.
\end{abstract}

(C) The Author(s) 2019

\footnotetext{
${ }^{1}$ Department of Physics and Technology, University of Bergen, P.O. Box 7803, 5020, Bergen, Norway. ${ }^{2}$ Department of Computing, Mathematics and Physics, Western Norway University of Applied Sciences, P.O. Box 7030, 5020, Bergen, Norway. ${ }^{3}$ Department of Nuclear Engineering, North Carolina State University, Raleigh, NC, 27695-7909, USA. ${ }^{4}$ Department of Electrical Engineering, Western Norway University of Applied Sciences, P.O. Box 7030, 5020, Bergen, Norway. Correspondence and requests for materials should be addressed to K.S.Y.-H. (email: kristian.ytrehauge@uib.no)
} 